\title{
Creatividad y sentido en el investigador educativo
}

\section{Nora Elizondo Schmelkes}

Profesora investigadora Instituto Humanista de Psicoterapia Gestalt, Querétaro

\section{Resumen}

$\mathrm{E}$ ste trabajo presenta el tema de la creatividad como dirección para fomentar el pensamiento reflexivo, crítico y estratégico en la investigación educativa, y como una parte crucial en el sentido e identidad del investigador, ya sea de manera individual, familiar, laboral y social, con la finalidad de que éste se desarrolle y pueda enfrentar los retos presentes y futuros. Fomentar la creatividad en la investigación educativa es un camino que permite el desarrollo del potencial del investigador. Los elementos cotidianos de la creatividad pueden ser la herramienta más cercana que tiene el investigador para desarrollarla y traer un sentido a su vida que se refleje en beneficios para sí mismo, su labor como investigador y su entorno.
Palabras clave: creatividad, investigación educativa, sentido, investigador.

\section{Introducción}

La investigación en el campo educativo trata cuestiones relativas a la búsqueda y desarrollo del conocimiento en ese ámbito (Arnal, et al. 1994), cuyo proceso requiere de diferentes capacidades como son la curiosidad, el descubrimiento, el pensamiento reflexivo, la observación, el análisis y muchas otras habilidades que el investigador desarrolla como parte de sí mismo. Entre ellas, la creatividad es una fuerza interna del investigador, que da impulso tanto a su actividad dentro de la investigación, como a su formación personal.

Existen muchas creencias y paradigmas relacionados con la creatividad. Frecuente- 
mente se relaciona con el arte y se le concibe como un don que solo unos cuantos poseen. Sin embargo, la creatividad es una capacidad potencial del ser humano que puede ser desplegada en todas las áreas de la vida cotidiana, ya sea personal, laboral, familiar o social. La creatividad es una habilidad que toda persona posee, se dé cuenta de ello o no. Cada día se utiliza la creatividad para realizar actividades y para la toma de decisiones como vestirnos, cocinar o simplemente realizar ajustes a los pequeños o grandes cambios que conlleva la vida diaria; también se emplea en tareas de alta complejidad dentro del trabajo, que involucran la investigación y sobre todo la solución de problemas.

La creatividad como parte del proceso de la investigación educativa lleva a tomar conciencia de cómo y para qué se utiliza la teoría y la metodología, con la finalidad de fomentar y contribuir al desarrollo del conocimiento y del entorno en el que vive cada investigador, ya sea familiar, laboral, institucional o social.

La creatividad puede ser utilizada de manera trasversal en todos los ámbitos de la vida. Sin embargo, es mucho más trascendente cuando además se utiliza para fomentar el desarrollo y crecimiento personal de cualquier individuo como parte de su educación y formación, pues implica un proceso de ampliación de conciencia. Puesto que el individuo es el sostén de la familia, misma que sostiene a la sociedad, su desarrollo personal repercute en beneficios y cambios hacia una comunidad incluyente y busca impactar positivamente en los diferentes ámbitos de la vida cotidiana.
Este trabajo tiene como objetivo profundizar en la creatividad como parte crucial del desarrollo del ser dentro de la investigación educativa, dirigida hacia el desarrollo del investigador como centro de cualquier sistema al que pertenezca, a favor no solo de sí mismo, sino del entorno que lo rodea incluyendo otros seres humanos con los que interactúa, así como también del conocimiento que desarrolla a partir de su trabajo. Comprender la conceptualización de cada uno de los temas incluidos en el documento tiene que ver con la estructura del mismo.

Identificar la importancia del impacto que puede lograr el desarrollo de los elementos cotidianos de la creatividad aquí presentados como parte de la investigación educativa, lleva a aprovecharlos y fomentarlos en el desarrollo del potencial humano del investigador.

\section{Investigación educativa}

La investigación educativa se dirige de manera primordial hacia la solución de problemas y el desarrollo del conocimiento, comenzando por fijar una problemática y objetivo que permitan contar con una perspectiva que marque las acciones a seguir y que den sentido a dicha actividad. Puesto que implica la toma de decisiones, los valores y el sentido que tiene el investigador, estos son elementos que dirigen y marcan el desarrollo de su investigación, además del proceso riguroso y sistemático que exige cada enfoque metodológico. Sin embargo, es el investigador quien da sentido a sus acciones y decisiones dentro del proceso. 
Cuando se carece de sentido, es común evadir la responsabilidad, volverse a otros, perder la motivación y con ello, abandonar la investigación que se realiza. "El riesgo de quedarnos estancados en un pensamiento cómodo es mucho mayor de lo que nos atrevemos a admitir" (Rehn, 2000: 21). Situarse en lo cómodo y conocido acarrea que lentamente se disipe la capacidad innata de asombro y curiosidad y con ello, se vaya perdiendo el gusto por la investigación.

El razonamiento que se da en el pensamiento crítico, reflexivo y estratégico que requiere la investigación, permite procesar las experiencias educativas para darles sentido. Las habilidades de razonamiento están correlacionadas con la adquisición de significado (Lipman, 2003), esto exige un pensamiento de alto orden que conlleva un sinnúmero de actividades mentales como identificar relaciones, distinguir, conectar, evaluar, definir, cuestionar. Resnick (1987) menciona que el pensamiento de más alto orden involucra un conjunto de actividades mentales que requieren juicios críticos a partir del análisis de situaciones complejas y de acuerdo con criterios múltiples. Este tipo de pensamiento, por ser complejo, demanda esfuerzo y autorregulación por parte del investigador (Cromley, 2000).

En la investigación educativa, desarrollar el juicio crítico y constructivo permite ampliar las posibilidades hacia múltiples soluciones. Según Lipman (2003) el juicio crítico surge de las comparaciones que se hacen. Estas comparaciones implican un discernimiento entre las similitudes y diferencias que se observan ante alguna situa- ción que involucre cierto tipo de relación entre dos o más personas, objetos o situaciones mismas.

Es a partir de estos juicios con criterios múltiples, que el investigador construye su interpretación a través de las relaciones existentes que observa, así como sus discrepancias o por medio de la elaboración de nuevas relaciones que se ponen en evidencia. La interpretación que el individuo hace, particularmente en la investigación educativa y cualitativa, a partir de un juicio crítico y constructivo, es el vínculo entre el pensamiento y la acción. Utilizar la creatividad como estrategia para el desarrollo del investigador conduce al descubrimiento de posibilidades que dan sentido a lo que enfrenta y, a partir de ello, desarrolla los juicios críticos necesarios para su reflexión, determinación de sentido y significado propio al realizar su trabajo.

\section{Creatividad}

Si bien autores como Bohm (2002) consideran imposible definir la creatividad en palabras, durante años se ha estudiado este tema para arribar a un concepto holístico que no solo considere ambos hemisferios del cerebro, sino que además los integre como parte del proceso. Puesto que este término no tiene una definición clara, integral o universal, resulta fundamental diferenciar tres conceptos claves para adentrarse en el tema: creatividad, creación y co-creación. González (2002) define la creatividad como la "competencia transformativa en interacción con su entorno".

Así, la creatividad, hace referencia a esas posibles formas de desenvolverse 
(competencia) frente a las situaciones que requieren una reacción novedosa (transformación) en la vida cotidiana (relación con el entorno). Ello indica un potencial que toda persona posee, no una cualidad exclusiva de algunos; una persona puede ser considerada creativa al enfrentarse de manera novedosa con el medio en donde se desenvuelve en el día a día, sin importar de qué ámbito se trata. En el caso de la investigación educativa, basta con encontrar respuestas innovadoras y alternativas en el estudio que se realiza.

Ahora bien, una creación es considerada principalmente como el producto final, resultado de un proceso creativo. El creador es quien puede ofrecer un producto concreto tras haber experimentado un proceso en el cual su potencial creativo ha sido desplegado, encontrando vivencias novedosas. El investigador realiza este proceso a través de su trabajo.

Así, se puede afirmar que todos son creativos, pero no siempre son creadores. La diferencia radica en el proceso implicado. El proceso intermedio entre creatividad y creación, se identifica como co-creación, en donde todos los elementos, tanto de las personas involucrados como el entorno mismo en el que se encuentran, se conjugan y toman formas que terminan por dar un resultado específico. Puesto que el ser humano siempre está en relación con el entorno, el proceso de co-creación es inevitable y la investigación educativa, no es la excepción.

Algunos de los elementos que han sido aportados por diferentes autores en el es- tudio de la creatividad y que se encuentran identificados en el proceso de co-creación son fenómenos tales como la observación, abstracción, el uso de pautas, analogías, improvisación, modelado, el juego, la síntesis, el pensamiento corporal y dimensional y eso que algunos llaman inspiración (Root-Bernstain, 2000); o bien aspectos tales como la empatía, el sentido de pertenencia o "tribu", el elemento esencial (Robinson y Aronica, 2009); el pensamiento lateral y la imaginación (Bono, 2004); la originalidad, comunicación y técnicas del pensamiento creativo (Marín, 1995), o simplemente la actitud creativa (Maslow, 2008), así como también habilidades como la lectura de contexto o la resolución innovadora y un sinnúmero de cualidades que la caracterizan. Estos son elementos que se han aportado en estudios y desarrollo de la creatividad en las últimas décadas. Dichos elementos, unidos parcialmente o en conjunto, dan pie a un proceso de transformación creativa, similar a aquella que implica la investigación educativa.

Existen dos principales y cruciales aspectos para poder fomentar y desarrollar la creatividad como parte del proceso de investigación. El primero es aceptarlo, es decir, comprender qué es considerado como creatividad y lo que es un proceso creativo, además de aceptar que la investigación, per se, implica ambas. Sin embargo, es importante comprender que no es absolutamente necesario desarrollar todos los elementos implícitos en dicho proceso, sino que uno por uno pueden ir ampliando el proceso creativo y por lo tanto, la capacidad creadora del investigador. 
El segundo es enfrentar y eliminar cualquier tipo de barrera interna o externa, que implique un bloqueo o impida el desarrollo del proceso creativo (Towe, 2004; Ordóñez, 2010) o de una investigación. Las barreras internas son quizá las más difíciles de romper, pues suelen estar arraigadas profundamente ya que incluyen introyectos, creencias e ideas que pueden llevar instaladas en la mente desde la infancia, sean ciertas o no. Incluso, muchas veces las barreras externas, como recursos económicos escasos o los impedimentos institucionales, suelen ser el pretexto para ni siquiera enfrentar o lidiar con las internas. Esto no les quita que existan y que hay que enfrentarlas, lidiar con ellas y poder eliminarlas. Tomar riesgos es quizá uno de los factores más relevantes para que, en verdad, se dé un proceso creativo en la investigación. "Necesitamos aventurarnos en espacios donde las cosas son incómodas, incluso aterradoras, y donde nuestras habituales técnicas de navegación mental ya no son aplicables" (Rehn, 2011).

Cruzar las barreras, así como el proceso creativo y el desarrollo de la creatividad en la investigación educativa, no es tarea sencilla ni trivial. Sin embargo, los procesos creativos tienen también un lado simple y amable, donde están plasmados elementos cotidianos para desarrollar la creatividad como parte del proceso de investigación.

\section{Elementos cotidianos}

Los elementos cotidianos, tan mundanos como la diversión y la espontaneidad como propuesta metodológica de creación; la valentía de tomar riesgos como una al- ternativa de experimentación; hacer brillar a otros reconociendo sus cualidades desde un sentido de humildad y apoyo como fuente de inspiración, o el uso de la polaridades humanas (la luz y la sombra) como piedra angular para echar a andar la imaginación de las posibilidades, pueden ser quizá las herramientas más poderosas para desarrollar la creatividad, ya que el individuo suele tenerlos al alcance.

Estos elementos, en el ámbito educativo o no, unidos en conjunto, parcialmente o por separado, permiten comprender que ser testigos del proceso de creación que siguen otros, resulta tan inspirador que facilita la posibilidad de desarrollar procesos creativos propios, simplemente tomando elementos de la cotidianidad. Desarrollar uno o varios de estos elementos, puede significar el cambio de los procesos creativos en el investigador dentro de cualquier ambiente en el que se presente, ya sea para sí mismo o como proceso de innovación inspirador para otros que lo rodean. Con ello, cada uno de dichos elementos, mismos que se presentan a continuación, se pueden potenciar como parte de la creatividad e integrar en el proceso de investigación.

\section{Diversión}

La única dificultad que conlleva el juego... es la de poder ser lo suficientemente niños como para permitírnoslo

ROOT-BERNSTEIN

Es crucial entender que la diversión y el juego, así como la espontaneidad, deben ser desarrollados independientemente de la edad del individuo. Si bien los niños los 
usan constantemente y por lo tanto, los desarrollan de manera natural, es particularmente importante que los adultos utilicen el humor como un motivador de la creatividad.

La importancia del juego en la creatividad implica, de manera temporal, romper las reglas y transgredir las fronteras o límites de una actividad formal o seria, como lo es la investigación, para establecer la novedad movilizada a partir de la curiosidad, el interés y la diversión. El juego, rompe la monotonía creando espontaneidad e improvisación en los actos realizados. Los resultados del juego no se limitan al disfrute o goce por la actividad, sino que inyectan energía y vitalidad. El juego desarrolla y consolida todas y cada una de las herramientas del pensamiento (Root-Bernstein, 2000), lo cual deriva en la activación de ambos hemisferios del cerebro, fortaleciendo las diversas habilidades mentales y contribuyendo al proceso de investigar.

La espontaneidad que se llega a producir a partir del juego o viceversa, genera y promueve nuevas conductas, formas de observar, de percibir el entorno y crear. El juego permite liberar las preocupaciones y tensiones, dejando que lo que parece importante o el resultado, pase a un segundo plano. Una actitud lúdica despliega un horizonte de posibilidades para desarrollar. El sentido del humor ejercita el ingenio, integrar el juego en la vida cotidiana es una estrategia efectiva para el desarrollo del potencial creativo ya que impulsa a buscar e inventar nuevas alternativas que abren las posibilidades de la percepción e interpretación.
El juego, como parte del desarrollo de la creatividad en la investigación, proporciona la posibilidad del disfrute de dicho proceso. Poder cambiar la percepción de la investigación a una actividad disfrutable y divertida, genera motivación para realizarla. Como adultos y profesionistas, específicamente en el área educativa, incluir el sentido del humor, el juego, la espontaneidad y la diversión, engendra una visión innovadora, integradora y más alcanzable de esta actividad sin restarle la formalidad implícita.

\section{Valentía}

Tu corazón es fuerte, ten el valor de hacerle caso

Autor Desconocido

Ser valiente significa tomar riesgos que lanzan a lo desconocido, a lo nuevo, a lo inimaginable. Es una virtud del ser humano que entraña la fuerza de voluntad necesaria para llevar a cabo una acción a pesar de los obstáculos, impedimentos o dificultades que se encuentran en el camino. Involucra lidiar y enfrentar los miedos con coraje y sobreponerse a ellos para lograr lo deseado.

Ante el riesgo y el miedo, el investigador se enfrenta a su propia vulnerabilidad e incluso fragilidad como persona y eso en sí puede representar una amenaza o falta de seguridad. Ser susceptibles a la propia vulnerabilidad es parte de la existencia y delicadeza de ser humano. La valentía es una fuerza interna que se posee para enfrentar la incertidumbre que conlleva hacer una investigación. 
Como característica o elemento del proceso creativo, la valentía permite generar y canalizar el impulso requerido para romper barreras, enfrentar los miedos y obstáculos para inventar, innovar, crear. Descubrir al interior de cada uno la voluntad de modificar y transformar, conecta con el coraje requerido para tener el valor de ir hacia lo desconocido, buscar lo nuevo, aceptar lo incierto, acercase a sueños y deseos e impulsar el potencial creativo.

Desarrollar la valentía como parte de la creatividad, proporciona al investigador la posibilidad de correr el riesgo de tomar decisiones hacia la innovación, hacia nuevas formas de solucionar los retos y a enfrentar las situaciones o desafíos que se presenten.

\section{Hacer brillar a otros}

La imaginación creativa... facultad que nos permite pasar del nivel de

concepto, al acto

IGOR STRAVINSKI

Hacer el esfuerzo por observar, descubrir, aceptar, reconocer y apreciar las cualidades de otros habla de la aceptación de encontrar belleza y valor en cada ser humano. No siempre resulta fácil enfocarse en las maravillas del otro. Hacer brillar a otros muestra un deseo de hacer y buscar el bien común. Es poner la mirada en lo mejor del otro, no desde el optimismo, sino desde la integración y unión de esfuerzos y habilidades.

El proceso creativo requiere de inventiva e imaginación. Hacer brillar a otros es inventar junto con el otro y a través de él.
Lo que se imagina o conoce del otro puede permanecer en un estado tácito sin tomar una forma concreta. Inventar no sólo supone un descubrimiento y jeureka!, sino también aplicarlo, llevarlo a cabo. Así, reconocer al otro en sus potencialidades y ponerlo en práctica es un proceso de co-creación.

Hacer brillar a otros, identificando y reconociendo sus cualidades y capacidades, es parte de la creatividad que motiva la investigación educativa hacia el bien común con una visión holística de los beneficios que se pueden lograr tanto para el individuo, como para el entorno que le rodea. Un investigador, que además asesora a otros, puede desarrollar esta capacidad a través del trabajo de sus investigadores en formación.

\section{Humildad}

La humildad es la belleza de la espiritualidad ANDrew Murray

Reconocer las propias limitaciones y debilidades para actuar en consecuencia de dicho conocimiento, es parte de aceptar la vulnerabilidad y fragilidad como seres humanos y reconciliarse con la impotencia ante ello. Esta humildad permite el respeto y ser fieles a la propia existencia.

En el proceso creativo, la humildad juega un papel substancial ya que permite reconocer, aceptar, las limitantes y las cualidades. Crear sin buscar la aprobación de los demás o la fama, facilita la decisión de tomar riesgos y encontrar el coraje de ser valientes ante la novedad. Implica mirarse 
a uno mismo ante la grandeza de la vida misma y con ello, espejearse ante un mundo lleno de posibilidades en donde se puede recibir al otro tal cual es, y a la vez, ser recibidos por el otro.

La humildad como una actitud del investigador, implica apertura hacia el aprendizaje y hacia el trabajo colaborativo que deriva en un enfoque integrador de los elementos o actores que se ven involucrados en una problemática o reto estudiado.

\section{Posibilidades}

El mejor de los mundos posibles actualizaría cada posibilidad genuina, y el mejor de los mundos posibles contendrá todas las posibilidades

GotTFRIED VON LIEBNIZ

El proceso creativo invita a crear un sinnúmero de mundos en donde la combinación de dualidades y polaridades se hace posible. Ben Zander (2000) menciona que para impulsar la creatividad, hay que salirse de la caja. Esto implica poder traspasar los límites y hallar nuevas posibilidades.

Cada creación lleva a un mundo heterocósmico, en el cual los objetos son imposibles desde la realidad existente, pero posibles en nuevas realidades aún no definidas en una máxima variedad. Mundos ficticios que permanecen accesibles e incompletos hasta que se lleva a cabo el proceso creativo o una creación. Ideas creativas que están listas para ser descubiertas como parte de un objetivo de la investigación.

En la investigación, las ideas creativas generan cambios que atraen y transforman los entornos, ya sean laborales o sociales, para contribuir al conocimiento. Sin embargo, más allá de los procesos creativos, tanto en las ideas innovadoras que inspiran o en la creatividad como tal, el sentido que estos procesos detonan e impulsan en el ser humano, son los que favorecen su desarrollo y formación. Desarrollar los elementos mencionados como parte de la creatividad en el proceso de investigación, permite que el investigador le de un sentido propio a su formación y labor como tal.

\section{Sentido}

Nietzche dijo que "el hombre es el animal que se hace promesas a sí mismo" (en Fabry, 1977). Existe una promesa o preocupación intrínseca en cada investigador que, aunado a su sentido de existencia, vive con una intuición de darle una dimensión trascendental a su formación y labor en la investigación, probablemente relacionada con su contribución al desarrollo del conocimiento.

Los retos que implica una investigación, pueden llevar al investigador a sentir la vulnerabilidad que como categoría existencial del ser humano, lo conecta con el sentido de su vida y por ende, de su función como investigador y colaborador en el desarrollo del conocimiento. En la propia naturaleza finita del ser mortal se puede llegar a reconocer el sentido propio y trascender significados, ideas, creencias, deseos, valores... es decir, el sí mismo auténtico y su significado o sentido. El sentido que el investigador pueda dar a su trabajo será el impulso para llegar a enfrentar, resolver o resignificar cualquier situación, reto o desafío que 
encuentre. Esto es lo que verdaderamente implica la formación y labor como investigador.

Frankl (2004) consideraba que las fuerzas internas del ser constituyen la "voluntad de sentido", la cual es necesaria para formarse como investigador, realizar dicha labor y crearse una identidad como tal. La identidad de una persona se forma con las vivencias, experiencias, imágenes y símbolos, que ella misma va recolectando para formar su sí mismo y su individualidad. Cada situación o reto que enfrenta la persona, es una oportunidad de reintegrar su identidad y sentido. Desarrollar la creatividad dentro de la investigación, proporciona al investigador dicha oportunidad.

En el proceso de investigación, a través del desarrollo de la creatividad en sus diferentes elementos, el investigador puede encontrar un sentido como persona y profesionista. Su sentido como investigador y su desarrollo personal se impulsa a partir de un proceso de pensamiento creativo, reflexivo, crítico y estratégico dentro de su investigación.

Así, los beneficios de la creatividad en el desarrollo del proceso de investigación implican:

- Promover la abstracción y síntesis

- Invitar a mirar lo significativo y lo esencial

- Incrementar la capacidad de adaptación sin perder el objetivo

- Agudizar la mirada desarrollando el pensamiento crítico y pautas de impulso hacia la innovación
- Estimular el disfrute de los procesos

- Facilita el darle sentido a lo que se realiza

- Abrir posibilidades (trabajos, soluciones) invita a lo diferente y además lo integra

- Sembrar curiosidad que impulsa y energetiza

- Crear vínculos: fortalece relaciones y el compromiso

- Engendrar y proporcionar inspiración a sí mismo y a otros

- Generar sentido a la formación, labor e identidad como investigador

- Transformar con sentido y sin perder la intención

- Permitir soltarse y conectarse con la libertad

Afirmar la libertad supone tomar las riendas no solo de su investigación sino de la vida y estar determinados a significarla en un proceso de autorrealización constante. "La libertad...está en proporción con el grado con que afrontamos nuestro destino y vivimos en relación con él" (May, 1988: 78) lo cual confiere energía y fortaleza al investigador. El proceso creativo surge de lo más profundo del ser y permite llegar a sentir libertad. “...solo lo que surge de dentro lo analizas, lo pasas por tu criterio y te decides a ponerlo en práctica asumiéndolo; es tuyo y te hace libre" (De Mello, 1999).

Así, el proceso creativo en la investigación lleva a experimentar una libertad aunada a sensaciones de plenitud y satisfacción, de poder volar, de ser capaces, de 
autenticidad, de independencia y logro; la sensación de abrirse a nuevas posibilidades. Esta libertad experimentada da sentido como parte del proceso creativo y resulta un motivador poderoso para el investigador, ya sea en su formación, en su labor o en su identidad como tal.

El desarrollo de un investigador como persona, como base de la sociedad en la que vive, deriva en un resultado para el beneficio del desarrollo humano que ya no es de uno y no es de nadie sino de todos, al igual que el conocimiento que genera a partir de su investigación.

\section{Conclusión}

Las exigencias de los subsistemas sociales y los inminentes e inevitables cambios que se dan en la actualidad, llevan a cuestionarse y poner atención en las demandas cualitativas del ser humano dentro de la investigación educativa. Fomentar la creatividad es una de las estrategias para la vida del individuo, no solo para tomar decisiones personales, sino como investigador.

La creatividad brinda beneficios comunes al individuo, a su entorno y a los desafíos que actualmente se viven, desde la sobrepoblación, la educación o el daño ambiental, hasta el desarrollo económico, social y humano de México. La creatividad proporciona un sentido a cada reto que se enfrenta y permite dar un significado basado en los valores como individuo e investigador.

Los elementos mostrados en este trabajo son resultado de una investigación realizada en un ambiente creador a partir de elementos cotidianos, a través de la teoría sustentada, donde la experiencia fundamenta la creación de teoría. Cada uno de los elementos cotidianos presentados: la diversión, valentía, hacer brillar a otros, la humildad y las posibilidades, son ventanas a la voluntad de sentido que requiere el investigador y avivan el proceso creativo aplicable al desarrollo de cualquier investigación educativa. Cómo y qué actividades realizar para impulsar el desarrollo de la creatividad y del pensamiento creativo como estrategia en el desarrollo de la investigación educativa, depende de correr el riesgo de aceptar el reto para hacerlo.

La creatividad como estrategia que da sentido y conecta con una libertad responsable, es una herramienta que aún tiene mucho potencial por desarrollar y por lo tanto, es digna de atención hacia el desarrollo de la innovación a través del pensamiento reflexivo, crítico y estratégico de los investigadores educativos que crean a la gente y a la sociedad como fortaleza principal de México.

\section{Bibliografía}

Arnal, J. ET AL. (1994) Investigación educativa. Fundamentos y metodologías. Editorial Labor: Barcelona, España.

Bонм, D. (2002). Sobre la creatividad. Kairós. España.

Bono, E. (2004). El pensamiento creativo, el poder del pensamiento lateral para la creación de nuevas ideas. Paidós. México.

Cromley, J. (2000). Learning to think, learning to learn. What the science of thinking and learning has to offer adult education. National Institute for Literacy: USA

FABry, J. (1977). La búsqueda de significado. Fondo de Cultura Económica: México.

Frankl, V. (2004). El Hombre en busca de sentido. 5ta impresión. Herder: España.

GonzÁlez, A. (2002). Conceptualización de la creatividad en Prycrea. En Revista Cubana de Psicología. Vol. 19, No. 3. Universidad La Habana:Cuba. 
Lipman, M. (2003). Thinking in education. 2nd Edition. Cambridge University Press.USA

De Mello, A. (1999). Autoliberación interior. Lumen: Argentina.

May, R. (1988). Libertad y destino en psicoterapia. Desclee de Brouwer: España.

MARíN, R. (1995). La creatividad, diagnóstico, evaluación e investigación. Universidad Nacional de Educación a Distancia (UNED): España.

Maslow, A. (2008). La personalidad creadora. 9a Edición. Kairós: España.

Murray, A. (2010). Humility, the journey toward holiness. Read a Classic: USA

OrdóÑEz, R. (2010). Cambio, Creatividad e Innovación: desafíos y respuestas. Garnica: Argentina.

ReHN, A. (2011). Dangerous ideas when provocative thinking becomes your most valuable asset. Marshall Cavendish Business: UK

RESNICK, L. (1987). Education and learning to think. National Academy Press: USA.

Robinson, K. y Aronica L. (2009). El Elemento. Descubrir tu Pasión lo Cambia Todo. Grijalbo: México.

Root-BERnstein R. y M. (2000). El secreto de la creatividad. Kairós: Barcelona.

Towe, L. (2004). ¿Por qué no se me ocurrió? Creatividad. Fundación Fonfemental: España.

ZANDER, B. (2000). Leadership, an art of possibility. American Media: USA. 
